\title{
Clinical utility of risedronate in postmenopausal osteoporosis: patient considerations with delayed-release formulation
}

This article was published in the following Dove Press journal:

International Journal of Women's Health

II April 2012

Number of times this article has been viewed

\author{
Plamen Kinov' \\ Mihail Boyanov ${ }^{2}$ \\ 'Department of Orthopedics and \\ Traumatology, University Hospital \\ Queen Giovanna - ISUL, ${ }^{2}$ Department \\ of Internal Medicine, Clinic of \\ Endocrinology, University Hospital \\ Alexandrovska, Medical University \\ of Sofia, Sofia, Bulgaria
}

\begin{abstract}
Bisphosphonates are the most widely prescribed treatment for postmenopausal osteoporosis, secondary osteoporosis, and male osteoporosis. Notwithstanding their high effectiveness and favorable safety profile, the adherence to bisphosphonate treatment remains low. Different treatment strategies aim to improve the clinical effectiveness of bisphosphonate therapy. This review paper assesses the clinical utility of oral intermittent risedronate in the treatment of postmenopausal osteoporosis. The new delayed-release risedronate formulation is a safer and easy to use alternative to other risedronate therapy. Oral risedronate, a potent nitrogen-containing bisphosphonate, has been extensively studied using daily regimens. A new intermittent (weekly) dosing regimen confirmed its clinical effectiveness in relation to vertebral and nonvertebral fracture prevention. The absence of significant differences in the incidence of adverse effects confirmed the favorable tolerability of the weekly dosage. In efforts to improve patient adherence to treatment, an innovative, delayed-release formulation of risedronate, which ensures adequate bioavailability of the active compound when taken with food, was introduced. The once-weekly delayed-release formulation of risedronate proved to be noninferior to the daily dosage of risedronate in terms of bone mineral density and markers of bone turnover. In addition, the incidence of new morphometric vertebral fractures was comparable in both treatment regimens. The new delayed-release formulation of risedronate showed a favorable safety profile. Delayed-release risedronate is a promising, new, effective, and convenient alternative to current bisphosphonate treatments. It appears to allow better patient adherence to antiresorptive treatment.
\end{abstract}

Keywords: osteoporosis, risedronate, bisphosphonates, delayed-release, bone mineral density

\section{Introduction}

Osteoporosis has been recognized as a debilitating disease since the mid 1990s. ${ }^{1}$ The most common type is postmenopausal osteoporosis, but osteoporosis secondary to disease or drug use is not infrequent. The major consequences of osteoporosis are low-trauma fractures, which seriously impact patients' quality of life, mortality, and are a costly burden to the healthcare system. One in two women and one in four men above the age of 50 years will suffer an osteoporotic fracture. Data from the Dubbo Osteoporosis Epidemiology Study, in which women and men aged 60 years and over were followed up for up to 15 years, showed that the mortality-adjusted residual lifetime fracture risk is $44 \%$ for women and $25 \%$ for men. ${ }^{2}$ Fractures were associated with increased morbidity and mortality. ${ }^{3}$

Fortunately, powerful and reliable diagnostic and therapeutic tools are available to fight the "silent epidemic" of osteoporotic fractures. Bisphosphonates, selective 
estrogen receptor modulators, strontium ranelate, calcitonin, teriparatide, and estrogens are all used for the prevention or treatment of osteoporosis.

Oral bisphosphonates are the most widely prescribed antiresorptive treatment in postmenopausal osteoporosis, secondary osteoporosis, and male osteoporosis. They are effective in reducing the incidence of vertebral and nonvertebral osteoporotic fractures. Their effects are manifested relatively early (6-12 months after onset of treatment) and are prolonged. In efforts to improve patient compliance, bisphosphonates are applied in different modes of administration: daily, weekly, and monthly oral dosages, as well as intravenous formulations.

Alendronate, risedronate, and ibandronate are three oral formulations that have been used in clinical practice for nearly two decades. Various well designed, randomized control studies have shown their high effectiveness and favorable safety profile in treatment of postmenopausal osteoporosis. Alendronate significantly reduces the risk of hip, vertebral, and other clinical fractures at three years with more pronounced effects in women with postmenopausal osteoporosis. ${ }^{4,5}$ Risedronate reduces the incidence of vertebral and nonvertebral fractures in 3 years by $49 \%$ and $39 \%$, respectively. ${ }^{6}$ It also significantly reduces the risk of hip fractures in elderly women with osteoporosis. ${ }^{7}$ Oral daily and intermittent ibandronate have been shown to significantly reduce the incidence of clinical vertebral fractures in 3 years. ${ }^{8}$ However, due to poor patient adherence to treatment, clinical effectiveness with bisphosphonates is suboptimal.

This paper reviews the different modalities of administration of risedronate and their utility from a clinician's and patient's point of view. A literature search in the PubMed database (http://www.ncbi.nlm.nih.gov/pubmed) was performed and the following keywords were used: risedronate, clinical utility, patient considerations, patient preferences. Only good quality articles were selected such as double-blind randomized controlled trials (by the authors' discretion). The review is not systematic in the way meta-analyses such as the one published by Cranney et al are. ${ }^{9}$ It reviews the use of delayed-release risedronate in the light of the current developments of patient-friendly formulations. New delayed-release risedronate allows for a dosing regimen independent of food and drink intake with adequate bioavailability and pharmacological activity. It provides an answer to the major patient considerations regarding the efficacy, safety, tolerability, and simplicity of bisphosphonate use.

\section{Risedronate for the prevention of postmenopausal osteoporosis}

Risedronate was initially applied in oral daily doses of $5 \mathrm{mg}$. The large Vertebral Efficacy with Risedronate Therapy (VERT) studies, VERT-North America and VERT-multinational, demonstrated that in women with postmenopausal osteoporosis risedronate leads to an increase in bone mineral density (BMD) and a reduction in vertebral and nonvertebral fractures. ${ }^{6,10}$ Risedronate was shown to increase BMD in the lumbar spine by approximately $6.0 \%$ and by $1.6 \%-3.1 \%$ in the femoral neck. ${ }^{6,10}$ In the VERT-North America trial risedronate reduced the incidence of vertebral fractures by $65 \%$ in the first year and by $49 \%$ in 3 years along with a decrease of nonvertebral fractures by $39 \%$ in 3 years. The Hip Intervention Program trial was a randomized controlled trial with hip fracture incidence as the primary outcome. ${ }^{7}$ Risedronate was found to prevent hip fractures in the elderly (70-79 years) with osteoporosis, with a relative fracture risk of $0.6 \%$ over 2 years compared to a placebo (95\% confidence interval $0.4-0.9, P=0.009) .{ }^{7}$ Prolonged treatment with risedronate was also shown to be effective. A 6-7-year long extension study showed a significant reduction of fractures in the placebo group, which was then given active treatment with risedronate. The incidence of vertebral fractures was $7.4 \%$ and $6.0 \%$ for the placebo group put on risedronate and the original risedronate only group, respectively, during the sixth and seventh year. ${ }^{11}$ A large Cochrane meta-analysis of $5 \mathrm{mg}$ daily doses of risedronate confirmed the high efficacy in preventing vertebral, nonvertebral, and hip fractures, along with increased safety and tolerability. ${ }^{12}$ These results were further confirmed by the large meta-analysis by Cranney et al. ${ }^{9}$

\section{Adherence to treatment with oral bisphosphonates}

Pharmacological fracture prevention requires patient adherence to the prescribed dosing regimen of osteoporosis treatment. Adherence is suboptimal in all chronic diseases and this is the case in osteoporosis. When medication is not taken in accordance with the prescribed regimen, altered benefits or elevated additional risks can be observed. Patient adherence to treatment is usually met by compliance and persistence. The definitions for compliance and persistence were developed by the International Society for Pharmacoeconomics and Outcomes Research Medication Compliance and Persistence Work Group. ${ }^{13}$ Compliance is measured over a certain period of time and represents the 
percentage of doses taken as prescribed. Persistence refers to the act of continuing the treatment regimen for the prescribed period of time. It may be defined as "the duration of time from initiation to discontinuation of therapy."13 Clinical effects of treatment should be measured against patient's adherence to treatment (ie, how well patients take their medication and for how long).

Although the efficacy and safety of bisphosphonates have been proven beyond doubt, patient compliance and persistence remain poor. This is partly due to patients' concerns about drug-related side effects (mainly gastrointestinal), patients' lack of understanding or motivation, the asymptomatic nature of osteoporosis, and the inconvenient, complex dosing regimens. Another recent concern is the exaggerated fear of atypical fractures caused by the bisphosphonate itself. ${ }^{14}$ The administration requirements for oral bisphosphonates, such as risedronate, include taking the medication on an empty stomach after an overnight fast with 200-250 mL of water in the upright position and waiting for at least 30 minutes before taking regular meals, other drugs, or beverages. However, due to this inconvenience, a large proportion of patients on oral bisphosphonates (33.5\% in Ettinger et al's study) do not wait for the minimum of 30 minutes before initiating eating after dosing. ${ }^{15}$ In addition, oral bisphosphonates are contraindicated in patients with swallowing problems or gastroesophageal reflux. ${ }^{16}$ However, the gastrointestinal safety of risedronate has been confirmed in a pooled analysis of nine studies. ${ }^{17}$ Upper gastrointestinal tract side effects are experienced in $29.6 \%$ of the patients taking a placebo compared to $29.8 \%$ in the patients taking risedronate. Endoscopic studies conducted on a large patient sample show no significant differences among the treatment groups. ${ }^{17}$ Unfortunately, the fear of upper gastrointestinal side effects associated with the daily regimen is one of the major reasons preventing patients from taking the drug properly. New formulations replacing the need for daily intake are well accepted by patients.

\section{Clinical trials with intermittent oral risedronate}

Risedronate remains active on the bone surface for an extended period of time, which has led to the production of new formulations of risedronate with extended dosing intervals. The so-called "bridging concept" was then applied. This concept allows one to take advantage of the efficacy of the new, extended formulation of the bioavailability and the effect on the fracture risk surrogates, such as increasing BMD and suppressing bone marker levels, which are comparable with those of the daily formulation. Based on this concept the weekly dosage of risedronate is not inferior to the daily dosage in terms of BMD and markers of bone turnover. ${ }^{18}$ In addition, the incidence of new morphometric vertebral fractures is comparable in both treatment regimens. The efficacy and tolerability of risedronate once weekly compared to risedronate once daily have been further confirmed in a randomized double-blind 2-year study. ${ }^{19}$ During treatment with $5 \mathrm{mg}$ risedronate daily and $35 \mathrm{mg}$ risedronate weekly, the incidence of new vertebral fractures was $2.9 \%$ and $1.5 \%$, respectively, along with an incidence of nonvertebral fractures reported as adverse events (5.0\% and 4.9\%, respectively). ${ }^{19}$ No significant differences have been observed in the serious adverse events or gastrointestinal side effects rate. However, the convenience of risedronate application has been greatly improved with once-weekly dosing.

It was assumed that less frequent treatment intervals are conducive to better patient acceptance and compliance. Despite the introduction of weekly bisphosphonates, a high percentage of women are not optimally compliant with their osteoporosis treatment. ${ }^{20}$ It is reassuring that those women on weekly bisphosphonates have higher rates of compliance and persistence than those on daily regimens, but even they fall below the acceptable levels. ${ }^{20}$ Data from large retail pharmacy databases has also confirmed the higher adherence to therapy among patients on weekly versus daily therapy. ${ }^{21}$ This knowledge inevitably led to the development of less frequent dosing regimens. Monthly dosing of $75 \mathrm{mg}$ risedronate on two consecutive days in a month has been compared to $5 \mathrm{mg}$ risedronate taken daily. ${ }^{22}$ Mean percent changes in lumbar spine BMD (3.4\% versus 3.6\%) and bone turnover markers are significant and comparable in both treatment groups. Both treatments are safe and generally well tolerated. ${ }^{22}$ Similarly, a monthly regimen of risedronate $50 \mathrm{mg}$ taken on three consecutive days each month has BMD and bone turnover effects, in addition to a good safety profile, that are similar to those of $5 \mathrm{mg}$ of risedronate taken daily. ${ }^{23}$ This study was, however, not powered enough to detect noninferiority; therefore, future studies will be needed to examine this aspect of the treatment.

A Phase II, 6-month dose-ranging study compared the effects of monthly and daily risedronate in postmenopausal osteoporosis patients. ${ }^{24}$ Three monthly doses were tested-100, 150 , and $200 \mathrm{mg}$. The three doses proved to be equally safe and efficacious. However the $150 \mathrm{mg}$ monthly regimen is the one that most closely matched the $5 \mathrm{mg}$ daily treatment. ${ }^{24}$ The efficacy and safety of the $150 \mathrm{mg}$ risedronate once-monthly 
formulation was shown in a 2-year double-blinded study. ${ }^{25}$ The mean change from baseline in lumbar spine BMD was $3.4 \%$ in the $5 \mathrm{mg}$ per day group and $3.5 \%$ in the $150 \mathrm{mg}$ once monthly group. The mean percent changes of BMD in the hip and in the suppression of bone markers were similar in both treatment regimens. The same was true for the incidence of adverse events, such as upper gastrointestinal tract reactions. ${ }^{25}$

A summary of the major studies illustrating the different administration schemes of risedronate is shown in Table 1.

\section{Patient considerations with use of oral bisphosphonates}

Bisphosphonate efficacy, tolerability, and safety profile have been demonstrated in numerous clinical trials. However, compliance and persistence with antiresorptive treatments remain low. As a consequence, fracture prevention is not effective and is more costly. In a recent study, Halpern et al showed that patients with low (medication possession ratio $<50 \%$ ) versus high (medication possession ratio $\geq 80 \%$ ) adherence had a $37 \%$ higher risk of fracture. ${ }^{26}$ In the same patients, low adherence was associated with $12 \%$ higher all-cause medical costs and 59\% more all-cause hospitalizations. Even once-monthly regimens cannot ensure $100 \%$ compliance with osteoporotic treatment. A few studies have shown that compliance with once-monthly bisphosphonates is suboptimal and 1-year persistence is very close to that of weekly bisphosphonates. ${ }^{27}$ This is probably due to the fact that this approach cannot totally eliminate the patients' concerns. Generally, concerns are based on one's view of the efficacy of the medication, the severity of their illness, and their ability to control it with medication. In the case of bisphosphonates, there are particular patients' concerns due to the need to take risedronate on an empty stomach with plain water and remain in the upright position for at least 30 minutes thereafter. Some of the problems associated with these requirements include:

1. A great number of patients are taking multiple medications. A particular difficulty arises when other medications must be taken on an empty stomach such as levothyroxine or antihypertensive drugs.

2. Some of the patients are accustomed to doing their prescribed regular physical exercise just before breakfast. Many of them are concerned that they might provoke esophageal reflux and upper gastrointestinal adverse events.

3. Many of the patients with osteoporosis are suffering from anxiety or have multiple obsessive fears. One example is the fear of going out because falls and fractures might occur. There are many patients who feel that something might go wrong even when taking the bisphosphonate in the proper way. This is especially true when they want to go on vacations and travel to distant locations.

4. A few of the very old patients experience difficulties in following complex instructions due to dementia or other psychogenic or neurogenic conditions.

Studies focusing on patients' nonadherence have shown that it might lead to insufficient suppression of bone resorption, lack of sufficient BMD increase, and, more importantly, to diminished or no antifracture efficacy. ${ }^{28,29}$ Many patients

Table I The selected studies illustrating the different administration schemes of risedronate - data on fracture risk surrogates are presented

\begin{tabular}{|c|c|c|c|c|c|c|}
\hline Authors & $\begin{array}{l}\text { Number of } \\
\text { participants } \\
\text { completing } \\
\text { the study }\end{array}$ & $\begin{array}{l}\text { Study } \\
\text { duration }\end{array}$ & $\begin{array}{l}\text { Comparator to } \\
\text { the } 5 \mathrm{mg} \text { daily } \\
\text { dosage }\end{array}$ & $\begin{array}{l}\text { Spine BMD } \\
\text { increase }\end{array}$ & $\begin{array}{l}\text { Bone } \\
\text { markers }\end{array}$ & Main conclusion \\
\hline $\begin{array}{l}\text { Harris } \\
\text { et } \mathrm{al}^{19}\end{array}$ & 1127 & 2 years & $\begin{array}{l}35 \text { and } 50 \text { mg } \\
\text { once weekly }\end{array}$ & $\begin{array}{l}5.17 \%, 4.74 \% \text {, and } \\
5.47 \% \text { for the } 5 \mathrm{mg} \text {, } \\
35 \mathrm{mg} \text {, and } 50 \mathrm{mg} \\
\text { subgroups }\end{array}$ & $\begin{array}{l}\text { Similar based } \\
\text { on analysis } \\
\text { of variance }\end{array}$ & $\begin{array}{l}\text { Once-weekly doses are comparable } \\
\text { in efficacy and safety to the } 5 \mathrm{mg} \\
\text { daily dose }\end{array}$ \\
\hline $\begin{array}{l}\text { Delmas } \\
\text { et } \mathrm{al}^{22}\end{array}$ & 1229 & I year & $\begin{array}{l}75 \mathrm{mg} \text { on two } \\
\text { consecutive } \\
\text { days monthly }\end{array}$ & $3.4 \%$ versus $3.6 \%$ & $\begin{array}{l}\text { Similar in } \\
\text { both groups }\end{array}$ & $\begin{array}{l}75 \mathrm{mg} \text { on two consecutive days } \\
\text { was not inferior in efficacy and } \\
\text { safety versus } 5 \mathrm{mg} \text { daily }\end{array}$ \\
\hline $\begin{array}{l}\text { Racewicz } \\
\text { et } \mathrm{al}^{23}\end{array}$ & 98 & 6 months & $\begin{array}{l}50 \text { mg on three } \\
\text { consecutive } \\
\text { days monthly }\end{array}$ & $3.22 \%$ versus $3.42 \%$ & $\begin{array}{l}\text { Similar in } \\
\text { both groups }\end{array}$ & $\begin{array}{l}50 \mathrm{mg} \text { on three consecutive days } \\
\text { was similar to } 5 \mathrm{mg} \text { daily with } \\
\text { respect to suppressing bone } \\
\text { turnover and increasing BMD }\end{array}$ \\
\hline $\begin{array}{l}\text { Delmas } \\
\text { et } \mathrm{al}^{25}\end{array}$ & 1094 & I year & $\begin{array}{l}150 \mathrm{mg} \text { once } \\
\text { monthly }\end{array}$ & $3.4 \%$ versus $3.5 \%$ & $\begin{array}{l}\text { Similar in } \\
\text { both groups }\end{array}$ & $\begin{array}{l}\text { I } 50 \mathrm{mg} \text { once monthly is similar } \\
\text { in efficacy and safety to daily dosing }\end{array}$ \\
\hline
\end{tabular}

Abbreviation: BMD, bone mineral density. 
perceive the requirement to take risedronate on an empty stomach as inconvenient. In a study with alendronate, 33.5\% of patients stated that they were unable to or did not wait for 30 minutes before taking their breakfast. ${ }^{15}$ The major problem with this is the decreased absorption of bisphosphonates in the presence of food. Pharmacokinetic studies have reported very low bioavailability if bisphosphonates are taken in the prandial or postprandial state. ${ }^{30,31}$ In a study conducted on nursing home residents, the deviation from proper taking of the bisphosphonate was reflected by the lack of suppression of bone turnover markers. ${ }^{32}$ In another study the response of lumbar spine BMD to treatment was smaller (only $1.5 \%$ at month six) if risedronate was taken between or after meals, rather than when taken properly at least 30 minutes before breakfast (2.9\% increase in BMD at month six). ${ }^{33}$ Therefore, the instruction "before food or drink" might compromise the clinical benefit of the bisphosphonates.

One approach to overcome these difficulties is to use an intravenous route of administration. The intravenous formulations must, however, be applied by medical personnel. They are more costly and might be accompanied by a higher rate of adverse reactions, such as the flu-like syndrome. ${ }^{34}$

\section{The concept of delayed-release bisphosphonates}

Bisphosphonates strongly chelate polyvalent cations (mostly calcium and magnesium) from food. Consequently, absorption of oral bisphosphonates is severely inhibited in the presence of food. There are now more restrictions when taking risedronate prior to the first food or drink in the morning while adequate bioavailability is guaranteed. Novel approaches to overcome the " $30-60$ minutes before food or drink" requirement are in the form of newly developed enteric-coated $35 \mathrm{mg}$ risedronate tablets. They help risedronate to reach the duodenum and jejunum where substances that interfere with its absorption are scarce. The new formulation contains an additional chelating agent that binds cations (such as calcium) which may compromise the absorption of risedronate. This is a promising approach in light of the high percentage of patients who are not complying with the "30-60 minutes before food or drink" requirement.

The effectiveness of this new delayed-release $35 \mathrm{mg}$ risedronate formulation, which can be taken with or without food, was tested against the $5 \mathrm{mg}$ daily risedronate dose in a Phase III international study. ${ }^{35}$ Nine hundred and twenty-two women were randomized to either take a $5 \mathrm{mg}$ daily dose or a $35 \mathrm{mg}$ weekly dose at least 30 minutes before or immediately after breakfast. Noninferiority was tested in mean percent change in lumbar spine BMD (measured by dual-energy $\mathrm{X}$-ray absorptiometry) and suppression of bone turnover markers. The incidence of vertebral fractures was assessed by semiquantitative morphometric analysis. The least square mean percent change from baseline in lumbar spine BMD at week 52 was found to be $3.3 \%$ in the $35 \mathrm{mg}$ taken after breakfast weekly group and $3.1 \%$ in the $5 \mathrm{mg}$ daily group. Additionally, significant increases in BMD in all regions of the hip were also noted, with no significant differences between the classical and novel regimens (Figure 1). According to this finding, the novel $35 \mathrm{mg}$ delayed-release risedronate tablet taken just after breakfast is not inferior to the classical $5 \mathrm{mg}$ daily risedronate dose. The bone turnover markers were suppressed in all treatment groups (Figure 2). Surprisingly, reductions in urinary N-terminal telopeptide/ creatinine and serum C-terminal telopeptide levels were significantly greater in the novel $35 \mathrm{mg}$ risedronate after
A

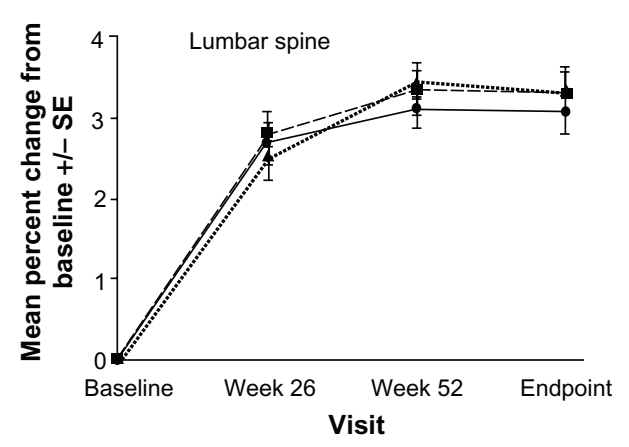

B

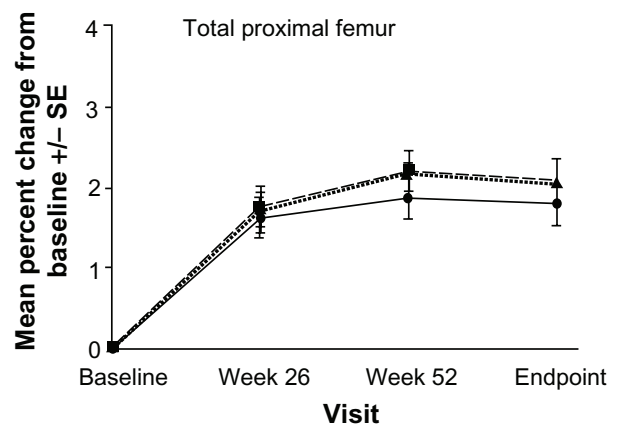

Figure I Mean percent changes from baseline in lumbar spine and total hip bone mineral density in women receiving $5 \mathrm{mg}$ risedronate daily ( - -), $35 \mathrm{mg}$ slow-release risedronate once weekly 30 minutes after breakfast (-

Reproduced with permission from McClung et al. ${ }^{35}$

Abbreviation: SE, standard error of the mean. 

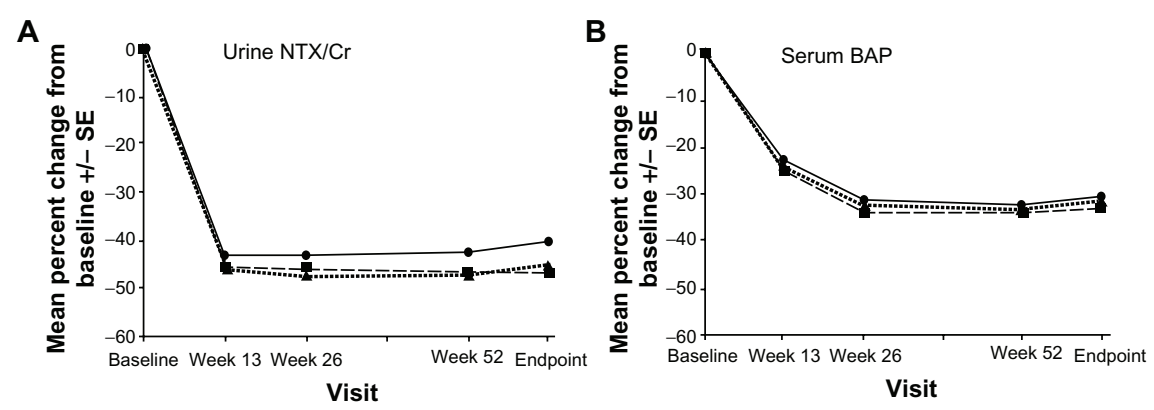

Figure 2 Mean percent changes from baseline in bone markers in women receiving $5 \mathrm{mg}$ risedronate daily ( - ), 35 mg slow-release risedronate once weekly 30 minutes after breakfast (_- - $)$, and $35 \mathrm{mg}$ slow-release risedronate before breakfast (ח-

Reproduced with permission from McClung et al. ${ }^{35}$

Abbreviations: BAP, bone alkaline phosphatase; $\mathrm{Cr}$, creatinine; NTX, N-terminal telopeptide; SE, standard error of the mean.

breakfast regimen than with the $5 \mathrm{mg}$ daily dosage. The authors suggested a slightly better bioavailability of the new formulation as a plausible explanation for this finding. The incidence of new morphometric vertebral fractures was very low and the study was not extensive enough to allow for comparisons. The adverse event profile was very similar in all treatment groups. However, in comparing the $35 \mathrm{mg}$ before breakfast and $35 \mathrm{mg}$ after breakfast regimens, there was an observed trend for higher incidences of upper absorptiometry tract adverse effects $(P=0.004)$. All of these events were mild to moderate. In conclusion, the novel formulation of $35 \mathrm{mg}$ risedronate taken after breakfast shows similar efficacy and safety as the $5 \mathrm{mg}$ daily dosage or the $35 \mathrm{mg}$ before breakfast formulation. It can, therefore, reduce the impact of food ingestion on compliance of osteoporosis patients through increased drug bioavailability and clinical utility. ${ }^{35}$ Future studies will have to determine whether the upright position is necessary for drug administration and what a reasonable time interval is for binding to calcium tablets and other cations.

This novel approach remains to be tested in male osteoporosis patients as risedronate is one of the few drugs which has been extensively tested and is indicated for this condition. ${ }^{36,37}$ It would be of interest to compare enteric-coated weekly risedronate tablets with the $150 \mathrm{mg}$ once-monthly formulation, which may be preferred by patients. ${ }^{38-40}$

\section{Clinical utility of bisphosphonates}

Clinical utility measures "cost" in relation to outcomes. It provides important information to help make choices between different treatments. Various studies have demonstrated the clinical effectiveness of bisphosphonates in preventing osteoporotic fractures and increasing bone mineral content. ${ }^{4-10,12,43}$ However, fracture reduction should be accomplished with a cost-effective therapy. Analyses of cost-effectiveness provide important information to healthcare providers who seek to allocate scarce resources with maximum effectiveness on a population level. Oral bisphosphonates have been in clinical use for treatment of osteoporosis for nearly two decades. However, fracture rates and associated medical costs remain high. Moreover, differences in the effectiveness of these drugs have not been investigated due to lack of head-to-head comparative, randomized controlled trials of oral bisphosphonates. Various randomized controlled trials provide evidence for reduction of fracture rates (vertebral and nonvertebral) with alendronate and risedronate. However, only ibandronate reduces the rate of vertebral fractures. The major challenge that health care providers face today is in reducing fracture risks through cost-effective therapy. Several studies investigate the clinical utility of the three most commonly used oral bisphosphonates (alendronate, risedronate, and ibandronate). ${ }^{41-43}$

In a large observational database analysis, cost, adherence, fracture risk, and total health care utilization were assessed in a population treated with oral bisphosphonates (alendronate, risedronate, and ibandronate). ${ }^{41}$ The authors reported low adherence to oral bisphosphonates measured by medication possession ratio (range $0.44-0.58$ ). During the study period of 36 months, the adherence rate for the three bisphosphonates dropped continuously. Although there was significantly lowered medication possession ratio with ibandronate at 24 months (ibandronate taken once monthly), the authors concluded that the rate of adherence in the study could be considered to be similar for all three bisphosponates. ${ }^{41}$ When considering fracture risk, there were no significant differences between risedronate, alendronate, and ibandronate. A cost comparison among the three oral bisphosphonates determined that patients on ibandronate had higher treatment-related costs than those using alendronate or risedronate. However, the adjusted 
difference among the three study groups was insignificant, which suggests that other factors may explain the observed cost difference. ${ }^{41}$ Similarly, there was no significant difference in adjusted fracture risk between risedronate-treated patients and alendronate or ibandronate users.

In the study by Tosteson et al, risedronate appeared to have the most favorable cost-effectiveness profile compared to alternative osteoporosis therapy (alendronate, ibandronate, parathyroid hormone. ${ }^{42}$

The difference in methodology makes it difficult to compare results from various studies. The lack of head-to-head comparisons in clinical trials of bisphosphonates does not provide a valid basis for utility evaluation. Moreover, conclusions drawn from studies with a relatively short duration (12-18 months) might add biases in a chronic disease such as osteoporosis. ${ }^{41}$

\section{Conclusion}

Multidimensional decisions about the usefulness, benefits, and drawbacks of particular bisphosphonates influence physicians' decisions in the treatment of osteoporosis. Factors such as cost, insurance coverage, physician and patient considerations, as well as alternative medications may influence decisions concerning osteoporotic treatment. Usually, the considerations in the decision-making process are effectiveness and/or cost-effectiveness. There is an ongoing debate about the clinical utility of different bisphosphonates. Many factors should be considered when choosing a treatment for postmenopausal osteoporosis, especially the treatment's clinical effectiveness, safety profile, patient adherence, and cost-effectiveness. This review provides additional insights into the effectiveness of oral bisphosphonates in terms of patient adherence, fracture rates, and treatment costs. Oral delayed-release $35 \mathrm{mg}$ risedronate administered once weekly is not inferior to the classical $5 \mathrm{mg}$ daily risedronate dosing regimen. The new intermittent formulation of risedronate suppresses bone turnover markers, significantly increases $\mathrm{BMD}$, shows low incidence of new morphometric vertebral fractures, and is well tolerated in the treatment of osteoporosis in postmenopausal women.

Patients' perspectives, which greatly influence adherence to a particular treatment, are usually ignored. A different approach is tested with the delayed-release $35 \mathrm{mg}$ risedronate to improve patients' compliance with antiresorptive therapy and to increase its efficacy in clinical practice. The new formulation, which is taken once weekly after breakfast, is a promising therapy for postmenopausal osteoporosis with respect to patient adherence to treatment and subsequent effectiveness of risedronate in clinical practice. Continuous efforts aimed at lowering direct and indirect health care costs, and proper selection of patients at risk for osteoporotic fractures will improve the clinical utility of oral bisphosphonates in preventing osteoporotic fractures.

\section{Disclosure}

The authors report no conflicts of interest in this work.

\section{References}

1. World Health Organization Study Group. Assessment of fracture risk and its application to screening for postmenopausal osteoporosis. Report of a WHO Study Group. World Health Organ Tech Rep Ser. 1994;843: $1-129$.

2. Nguyen ND, Ahlborg HG, Center JR, Eisman JA, Nguyen TV. Residual lifetime risk of fractures in women and men. $J$ Bone Miner Res. 2007;22(6):781-788.

3. Johnell O, Kanis JA. An estimate of the worldwide prevalence and disability associated with osteoporotic fractures. Osteoporos Int. 2006; 17(12):1726-1733.

4. Black DM, Cummings SR, Karpf DB, et al. Randomised trial of effect of alendronate on risk of fracture in women with existing vertebral fractures. Fracture Intervention Trial Research Group. Lancet. 1996; 348(9041):1535-1541.

5. Cummings SR, Black DM, Thompson DE, et al. Effect of alendronate on risk of fracture in women with low bone density but without vertebral fractures: results from the Fracture Intervention Trial. JAMA. 1998; 280(24):2077-2082.

6. Harris ST, Watts NB, Genant HK, et al. Effects of risedronate treatment on vertebral and nonvertebral fractures in women with postmenopausal osteoporosis: a randomized controlled trial. Vertebral Efficacy with Risedronate Therapy (VERT) Study Group. JAMA. 1999;282(14): 1344-1352.

7. McClung MR, Geusens P, Miller PD, et al. Effect of risedronate on the risk of hip fracture in elderly women. HIP Intervention Program Study Group. N Engl J Med. 2001;344(5):333-340.

8. Chesnut CH III, Skag A, Christiansen C, et al. Effects of oral ibandronate administered daily or intermittently on fracture risk in postmenopausal osteoporosis. J Bone Miner Res. 2004;19(8):1241-1249.

9. Cranney A, Tugwell P, Adachi J, et al. III. Meta-analyses of therapies for postmenopausal osteoporosis. III. Meta-analysis of risedronate for the treatment of postmenopausal osteoporosis. Endocr Rev. 2002; 23(4):517-523.

10. Reginster J, Minne HW, Sorensen OH, et al. Randomized trial of the effects of risedronate on vertebral fractures in women with established postmenopausal osteoporosis. Vertebral Efficacy with Risedronate Therapy (VERT) Study Group. Osteoporos Int. 2000;11(1):83-91.

11. Mellstrom DD, Sorensen OH, Goemaere S, Roux C, Johnson TD, Chines AA. Seven years of treatment with risedronate in women with postmenopausal osteoporosis. Calcif Tissue Int. 2004;75(8): 462-468.

12. Cranney A, Adachi JD, Guyatt G, et al. Risedronate for the prevention and treatment of postmenopausal osteoporosis. Cochrane Database Syst Rev. 2008;1:CD004523.

13. Cramer JA, Roy A, Burrell A, et al. Medication compliance and persistence: terminology and definitions. Value Health. 2008;11(1): $44-47$.

14. Compston JE. Bisphosphonates and atypical femoral fractures: a time for reflection. Maturitas. 2010;65(1):3-4.

15. Ettinger B, Pressman A, Schein J, Chan J, Silver P, Connolly N. Alendronate use among 812 women: prevalence of gastrointestinal complaints, noncompliance with patient instructions, and discontinuation. J Manag Care Pharm. 1998;4(5):488-492. 
16. Warner Chilcott. Actonel ${ }^{\circledR}$ prescribing information. February 2011. Available from: http://actonel.com/global/prescribing_information. pdf. Accessed December 28, 2011.

17. Taggart H, Bolognese MA, Lindsay R, et al. Upper gastrointestinal tract safety of risedronate: a pooled analysis of 9 clinical trials. Mayo Clin Proc. 2002;77(3):262-270.

18. Brown JP, Kendler DL, McClung MR, et al. The efficacy and tolerability of risedronate once a week for the treatment of postmenopausal osteoporosis. Calcif Tissue Int. 2002;71(2):103-111.

19. Harris ST, Watts NB, Li Z, Chines AA, Hanley DA, Brown JP. Two-year efficacy and tolerability of risedronate once a week for the treatment of women with postmenopausal osteoporosis. Curr Med Res Opin. 2004; 20(5):757-764.

20. Cramer JA, Gold DT, Silverman SL, Lewiecki EM. A systematic review of persistence and compliance with bisphosphonates for osteoporosis. Osteoporos Int. 2007;18(8):1023-1031.

21. Recker RR, Gallagher R, MacCosbe PE. Effect of dosing frequency on bisphosphonate medication adherence in a large longitudinal cohort of women. Mayo Clin Proc. 2005;80(7):856-861.

22. Delmas PD, Benhamou CL, Man Z, et al. Monthly dosing of $75 \mathrm{mg}$ risedronate on 2 consecutive days a month: efficacy and safety results. Osteoporos Int. 2008;19(7):1039-1045.

23. Racewicz AJ, Schofield PJ, Cahall DL, Cline GA, Burgio DE. Monthly dosing with risedronate $50 \mathrm{mg}$ on three consecutive days a month compared with daily dosing with risedronate $5 \mathrm{mg}$ : a 6-month pilot study. Curr Med Res Opin. 2007;23(12):3079-3089.

24. Ste-Marie LG, Brown JP, Beary JF, et al. Comparison of the effects of once-monthly versus once-daily risedronate in postmenopausal osteoporosis: a phase II, 6-month, multicenter, randomized, doubleblind, active-controlled, dose-ranging study. Clin Ther. 2009;31(2): 272-285.

25. Delmas PD, McClung MR, Zanchetta JR, et al. Efficacy and safety of risedronate $150 \mathrm{mg}$ once a month in the treatment of postmenopausal osteoporosis. Bone. 2008;42(1):36-42.

26. Halpern R, Becker L, Iqbal SU, Kazis LE, Macarios D, Badamgarav E. The association of adherence to osteoporosis therapies with fracture, all-cause medical costs, and all-cause hospitalizations: a retrospective claims analysis of female health plan enrollees with osteoporosis. J Manag Care Pharm. 2011;17(1):25-39.

27. Hadji P, Claus V, Ziller V, Intorcia M, Kostev K, Steinle T. GRAND: the German retrospective cohort analysis on compliance and persistence and the associated risk of fractures in osteoporotic women treated with oral bisphosphonates. Osteoporos Int. 2012;23(1):223-231.

28. Eastell R, Vrijens B, Cahall DL, Ringe JD, Garnero P, Watts NB. Bone turnover markers and bone mineral density response with risedronate therapy: relationship with fracture risk and patient adherence. $J$ Bone Miner Res. 2011;26(7):1662-1669.

29. Caro JJ, Ishak KJ, Huybrechts KF, Raggio G, Naujoks C. The impact of compliance with osteoporosis therapy on fracture rates in actual practice. Osteoporos Int. 2004;15(12):1003-1008.
30. Barrett J, Worth E, Bauss F, Epstein S. Ibandronate: a clinical pharmacological and pharmacokinetic update. J Clin Pharmacol. 2004; 44(9):951-965

31. Ogura Y, Gonsho A, Cyong JC, Orimo H. Clinical trial of risedronate in Japanese volunteers: a study on the effects of timing of dosing on absorption. J Bone Miner Metab. 2004;22(2):120-126.

32. Agrawal S, Krueger DC, Engelke JA, et al. Between-meal risedronate does not alter bone turnover in nursing home residents. $J$ Am Geriatr Soc. 2006;54(5):790-795.

33. Kendler DL, Ringe JD, Ste-Marie LG, Vrijens B, Taylor EB, Delmas PD. Risedronate dosing before breakfast compared with dosing later in the day in women with postmenopausal osteoporosis. Osteoporos Int. 2009; 20(11):1895-1902.

34. Hamdy RC. Zoledronic acid: clinical utility and patient considerations in osteoporosis and low bone mass. Drug Des Devel Ther. 2010; 4:321-335.

35. McClung MR, Miller PD, Brown JP, et al. Efficacy and safety of a novel delayed-release risedronate $35 \mathrm{mg}$ once-a-week tablet. Osteoporos Int. 2012;23(1):267-276.

36. Ringe JD, Farahmand P, Faber H, Dorst A. Sustained efficacy of risedronate in men with primary and secondary osteoporosis: results of a 2-year study. Rheumatol Int. 2009;29(3):311-315.

37. Boonen S, Orwoll ES, Wenderoth D, Stoner KJ, Eusebio R, Delmas PD. Once-weekly risedronate in men with osteoporosis: results of a 2-year, placebo-controlled, double-blind, multicenter study. J Bone Miner Res. 2009;24(4):719-725.

38. Rackoff P. Efficacy and safety of risedronate $150 \mathrm{mg}$ once a month in the treatment of postmenopausal osteoporosis. Clin Interv Aging. 2009;4:207-214.

39. Casadei K, Becker C. Once-monthly risedronate for postmenopausal osteoporosis. Int J Womens Health. 2010;1:1-9.

40. Moro-Alvarez MJ, Diaz-Curiel M. Risedronate once monthly: a potential new regimen for the treatment of postmenopausal osteoporosis. Clin Interv Aging. 2008;3(2):227-232.

41. Martin KE, Yu J, Campbell HE, Abarca J, White TJ. Analysis of the comparative effectiveness of 3 oral bisphosphonates in a large managed care organization: adherence, fracture rates, and all-cause cost. J Manag Care Pharm. 2011;17(8):596-609.

42. Tosteson AN, Burge RT, Marshall DA, Lindsay R. Therapies for treatment of osteoporosis in US women: cost-effectiveness and budget impact considerations. Am J Manag Care. 2008;14(9):605-615.

43. White HJ, Bettiol SS, Perera R, Roberts NW, Javaid MK, Farmer AJ. A systematic review assessing the effectiveness of interventions to improve persistence with anti-resorptive therapy in women at high risk of clinical fracture. Fam Pract. 2010;27(6):593-603
International Journal of Women's Health

\section{Publish your work in this journal}

The International Journal of Women's Health is an international, peerreviewed open-access journal publishing original research, reports, reviews and commentaries on all aspects of women's healthcare including gynecology, obstetrics, and breast cancer. Subject areas include: Chronic conditions (migraine headaches, arthritis, osteoporosis);

\section{Dovepress}

Endocrine and autoimmune syndromes; Sexual and reproductive health; Psychological and psychosocial conditions. The manuscript management system is completely online and includes a very quick and fair peer-review system. Visit http://www.dovepress.com/ testimonials.php to read real quotes from published authors. 